\title{
Using genetics to unearth our path on earth
}

O n April 13, the National Geographic Society launched the Genographic Project. The $\$ 40$ million project is a 5-year effort to map the migration of humans from Africa to the regions inhabited now.

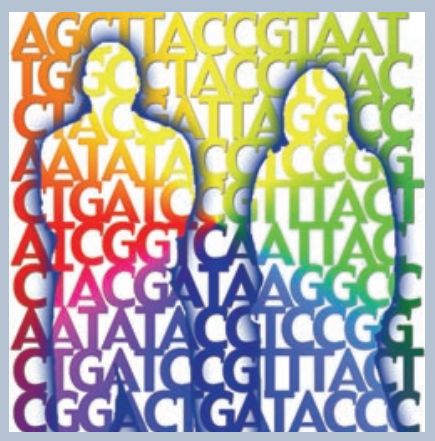

Image courtesy of the NIH.
Anthropological geneticist Spencer Wells, known for his hypothesis that all humans descended from a single African ancestor who lived 60,000 years ago, heads the project team. To uncover the paths that lead from this African "Adam" to every living human, the team will study genetic material from more than 100,000 samples, taken from indigenous people and the general public all over the world.

"This project will show us some of the routes early humans followed to populate the globe and paint a picture of the genetic tapestry that connects us all," Wells said.

Ten research centers will collect and analyze DNA from both parental lineages of each subject by taking samples from the paternally inherited Y chromosome and maternally inherited mitochondrial
DNA. Random natural mutations, called markers, are passed on through generations more or less unchanged, which allows scientists to trace how people are related. Once a marker appears in a person, all of that person's descendants will carry it, said Wells. After a marker is identified, geneticists will use computer algorithms to trace the mutations back to their first occurrence, allowing experts to uncover early migratory patterns.

The data are expected to constitute the largest collection of human population genetic information. "We're trying to figure out where we came from. It's a very simple human question," said Wells.

\section{Stacie Bloom}

\section{Coordinating cord blood efforts}

- xperts are making an effort to set up a national network of umbilical cord blood banks to coordinate collection and distribution of these cells. But they must first figure out how to establish and fund such a network so that physicians will be able to provide patients with suitable cells in a timely manner.

According to the Institute of Medicine (IOM), cord blood stem cell transplants have, in recent years, saved the lives of roughly 20,000 Americans with leukemia, lymphoma, sickle cell anemia, and several other illnesses. Umbilical cord blood is a useful source of hematopoietic progenitor cells, the same multipotent blood stem cells found in the bone marrow.

"[Cord blood] provides increased access to transplantation therapy for patients in need of a stem cell transplant who can't identify a matched related or unrelated donor," said Joanne Kurtzberg, director of the Pediatric Blood and Marrow Transplant Program at Duke University.

Most patients who need a hematopoietic progenitor cell transplant do not have a relative whose cells are a suitable match and must rely on public bone marrow registries or umbilical cord banks. But there currently aren't enough units of cord blood to meet the demand from the 11,700 Americans who could benefit from a transplant each year. As a result, thousands of patients die waiting for a match.
Because cord blood is readily available and virus free, Kurtzberg said, it's convenient for patients who need to go to transplant rapidly and don't have time to search for an unrelated adult donor.

Since the late 1980 s, collection of newborn cord blood has increased sharply. By 2003 , nearly 80,000 families in the US took advantage of any 1 of the 22 public banks that have been established to utilize cord blood. "Cord blood stem cells are a valuable addition to the armamentarium of transplantable tissues for transplant physicians," Naomi Luban, director of Transfusion Medicine at Children's National Medical Center in Washington, D.C., told the JCI.

There are major limitations to using cord blood, however. Kurtzberg points out that there is no central coordination, not enough federal funding to build adequate inventory, lack of standardization of banking criteria to ensure quality standards among banks, and lack of a single search registry listing all available unrelated donors for transplantation. "Currently transplant centers must approach multiple banks for each donor search," she said.

Lawmakers introduced a bill that addressed these issues in both the House of Representatives and the Senate earlier this year. The bill is still pending and has been referred to the House Subcommittee on Health. It would help to establish a national umbilical cord blood stem cell bank network and authorize $\$ 15$ million in federal funds during 2006 and $\$ 30$ million during 2007 to subsidize efforts to collect, process, test, freeze, and store cord blood stem cells to be used in transplant treatments. The network would also support peer-reviewed research using these cells. "The proposal of the US Congress to earmark dollars to the establishment of a cord blood banking program represents an important advance in the field of hematopoietic stem cell transplantation," said Vanderson Rocha, clinical coordinator of the Eurocord Project and board member of the Netcord organization.

The need for a central coordinating network is also the focus of a report released April 18, 2005 by the IOM. The report recommends that a new cord blood coordinating center - similar to the existing

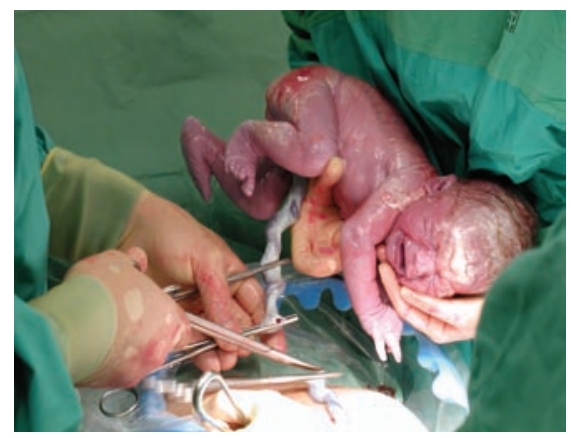

Umbilical cord blood taken from a neonate for future transplant use. Photos courtesy of Gesine Koegler, Düsseldorf Cord Blood Bank. 
National Marrow Donor Program - be set up to ensure a standardized and interconnected national system to cost-effectively store and distribute these cells. The Bush administration is studying the IOM report but has not yet determined its next step.

The proposed center would strengthen the network of cord blood banks and allow physicians to meet the needs of more patients who require transplantation therapies with a high-quality stem cell product, Rocha said. To build an adequate supply of cord blood for transplantations, the IOM concluded that the nation would need about 100,000 donations, in addition to the useable 50,000 cord blood donations already in stock at various public cord blood banks around the country.

Increasing the amount of inventory would assure that more people find a suitable match. "The matched cells are useful because they are frozen, so one does not need to depend on a live donor's availability," Luban told the JCI. But, she adds, "One cannot go back to the donor for additional transplantable cells or for other donor-derived cells.”

Another factor that restricts the clinical utility of cord blood stem cells is that use of these cells to treat other patients, called allogenic transplantation, could be associated with recipient immune rejection against donor cells. According to Luban, the small volume and low percentage of cells expressing CD34, an antigen selectively expressed on human hematopoietic progenitor cells, are also limiting factors.

The limitations due to the fact that cord blood stem cells are rare can be resolved through new expansion techniques, said Jonathan Leor, head of the Neufeld Cardiac Research Institute at Sheba Medical Center in Tel Aviv. Based on his experience, Leor believes that there is a high probability that the cells obtained from cord blood could be expanded in vitro and used for myocardial repair and angiogenesis. Clinical trials are also underway to assess the effects of using 2 cord blood units for a single patient, Rocha said.

Most important, many recent clinical retrospective studies in children and in adults show that the results of unrelated cord blood cell transplants are similar to those of unrelated bone marrow transplants. "Transplantation in children tends to have a good outcome with a minimum dose of cells," said Derwood Pamphilon, a consulting hematologist for the United Kingdom's National Blood Service. Even in adults, he continued, a reasonable dose of cord blood cells, even with a minor degree of mismatch, gives an outcome much better than had been hoped for.

\section{Stacie Bloom}

\section{The life sciences, according to Didier Trono}

$D$ idier Trono has been dean of the School of Life Sciences, a new entity at The Swiss Federal Institute of Technology Lausanne (EPFL), since October 1, 2004. The JCI talked to Trono, a prominent HIV researcher and former clinician, about his first 6 months on the job and about the ups and downs of starting a life sciences school at a renowned technology institute.

JCI: How were you selected for this position?

Trono: I was selected through an international search process. JCI: What are your main goals as dean?

Trono: The School of Life Sciences is the new kid on the block at EPFL, born from the strong belief that biomedical research will reach new frontiers by integrating quantitative approaches and technologies yielded by the hard sciences. There is an incredible thirst for biological questions amongst our colleagues here from chemistry, physics, mathematics, computer science, engineering, and so on. Also, the EPFL bachelor and master programs, its very international faculty, and its lakeside campus attract some of the very best students not only from Switzerland and other European countries but also from the rest of the world.

[This is] a unique opportunity to create a top-level biomedical research institution, where the traditional life sciences fortes of the Geneva-Lausanne region, in genetics, molecular and cellular biology, are taken to new dimensions within the setting of a leading institute of technology. My responsibility as dean is to help this vision come true.

JCI: What does your research focus on?

Trono: The main focus of my laboratory has been for many years the molecular biology of HIV infection with, lately, a special interest in innate cellular factors that confer resistance against retroelements, be it HIV itself, hepatitis B virus, or endogenous retroelements. A few years back, our HIV work led us to develop lentiviral vectors. We keep exploring their potential for human gene therapy and as tools for the study of mammalian genetics.
JCI: Do you plan to continue this work, or are your duties mostly administrative now?

Trono: Basic research has been a passion from the day I entered David Baltimore's laboratory after completing my clinical training in infectious diseases, and I made it very clear before accepting the EPFL job that I would keep doing research. If anything, running a lab places me in a perfect spot to judge whether what we are putting

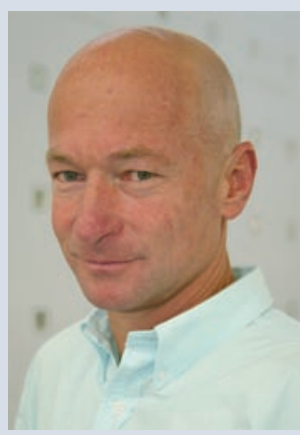

Didier Trono, dean of the new School of Life Sciences at EPFL. in place is working or not.

JCI: Will you describe your typical day?

Trono: Waking up a bit after 5, clearing up nightly e-mails, brushing through a newspaper for some update on the world, starting with the all-important sports section ... And that is about it for the routine. The rest is faculty recruitments, core facilities organization, discussions with architects on the building that will add 10,000 square meters of research space to our school within a couple of years. And many discussions with my colleagues on how best to foster our fast-growing programs in cancer research, developmental biology, neurosciences, infectious diseases, structural biology. And for dessert, breezing through the lab and debating with students and postdocs on the implications of their latest result and on the smartest way to get yet one step closer to [answering] the questions that keep us awake at night.

JCI: When you leave, what do you hope to have accomplished?

Trono: [To have] saved the world. But don't repeat it, in case I come up short ...

Stacie Bloom 